\title{
FACILITATING ENGAGEMENT AND BELONGING FOR STUDENTS WITH DISABILITIES: USING EXPRESSIVE ARTS
}

\author{
Rebecca M. Murray, Barry University \\ Heidi LaPorte, Barry University
}

Four volunteer participants who used the services of the Office of Accessibility Services (OAS) on our campus attended three sessions where they were interviewed about inclusivity and (a) taught an art technique; (b) taught to do the technique with a partner; and (c) used the technique with a guest whom they identified as having impacted their inclusivity on campus. The qualitative method of phenomenology was used to analyze transcripts from the interviews and the art sessions. The information the participants provided revealed the essential themes of (a) The desire for support beyond academic accommodations; (b) The benefits of an expressive arts program; and (c) The meaning of inclusivity and the desire for engagement and belonging. We detail the thematic findings of the study and make recommendations for how OASs can expand the services they provide. We advocate for creating expressive arts programing to facilitate engagement and belonging for students with disabilities

The Americans with Disabilities Act (1990) requires colleges and universities to provide reasonable accommodations to students with disabilities so that they may participate in all aspects of postsecondary education on an even playing field with students who do not have disabilities. Offices of Accessibility Services (OAS) are established within postsecondary educational institutions to oversee the process of connecting students with disabilities to the resources and accommodations they need for equity. This is arguably the primary function of OASs. However, much more can be done beyond ensuring accommodations.

The OAS at our institution wants to provide expanded services to students with disabilities. Taking our cues from the literature suggesting that engagement and a sense of belonging are critical factors in student success and the findings that engaging in expressive arts has multiple benefits, we piloted an arts program for students with disabilities through our University OAS. We collected qualitative data during the three sessions of the project. Results were analyzed using the qualitative method of phenomenology. They revealed three essential themes: namely that students with disabilities may benefit from more than just accommodations, that they want inclusivity, engagement, and belonging, and that an expressive arts program is one way to provide engagement and belonging effectively.

The review that follows establishes that a significant number of students with disabilities seek higher education and that these students often need additional support to bolster their persistence and to finish their degrees. Student engagement has been correlated with retention and academic success, and after introducing some of that literature, we review work that establishes the importance of engagement for students with disabilities. Lastly, we examine the literature suggesting that students with disabilities may benefit from affinity groups. OAS offices are uniquely positioned to establish such groups. We present a review of why an expressive arts program may facilitate engagement and a sense of belonging for students with disabilities. 


\section{AN OVERVIEW OF HIGHER EDUCATION AND STUDENTS WITH DISABILITIES}

Data from the U.S. Department of Education (2021) indicate that almost 20\% of college/university students have a disability. These students are often given academic accommodations, but students with disabilities obtain approximately $18 \%$ fewer degrees than their peers without disabilities (Bureau of Labor Statistics, 2016). Thus, it appears that academic accommodations alone may not be enough support.

Teasing out what would be helpful to students with disabilities beyond academic accommodation is difficult, in part because they are often grouped for research purposes, so the literature on recommended support is murky (Kimball et al., 2017). The disabilities represented among college/university students are almost as diverse as those in the general population. College students most frequently report hidden disabilities such as ADHD and other neurodevelopmental disorders, but an array of other disabilities is likely to be found in any student population. Are the extracurricular needs of students with low vision or mobility challenges the same as those with a learning disability or a mental health diagnosis?

Answers to questions about intersectionality among students with disabilities and their specific needs are tangled and complicated. This is partly why Kimball et al. (2017) recommend that colleges and universities engage students with disabilities. As they note, engagement has been found to benefit students both academically and non-academically. Students involved in learning communities attain more knowledge and show greater persistence. Engagement, in general, has been correlated with positive interactions with both peers and faculty. Moreover, it is well established that student engagement is correlated with retention (Kuh, 2001; Kuh et al., 2005; Lam et al., 2012).

\section{STUDENT ENGAGEMENT}

What does it mean for a student to be engaged on campus? A review of this multifaceted concept is beyond the scope of the current literature review, but most definitions include a behavioral, social, and emotional component. Behaviorally, engaged students participate in their institution's academic and social opportunities. Social engagement refers to how well students interact with their peers, faculty, and other members of the college/university community. Emotional engagement involves affective connection such that students identify with their school and feel that they belong (Zhoc, 2019).

In her article about student engagement, Komives (2019) noted that students have sought formal and informal ways to gather around shared interests and experiences since the beginning of postsecondary education. She also pointed out that researchers have repeatedly demonstrated that student engagement outside the classroom is associated with greater persistence and better academic performance. There is evidence that student engagement is correlated with retention and even health outcomes (Tinto, 2012; Walton \& Cohen, 2011). Kuh et al. (2005) asserted that "what students do during college counts more for what they learn and whether they will persist in college than who they are or even where they go to college" (p. 8). Newman et al. (2020) found that when students with disabilities engage with standard or disability-related supports on campus, they are more likely to be academically persistent and complete their degrees.

\section{THE IMPORTANCE OF ENGAGEMENT FOR STUDENTS WITH DISABILITIES}

Strayhorn (2012) looked at students with various intersectionality and argued that special attention should be paid to members of any marginalized group. Evidence suggests that these students may feel less of a sense of engagement and belonging on campus than those with privileged identities. College and university campuses were developed for affluent white men. Even today, the people other than this historical norm may need extra support to feel they belong. Indeed, Johnson et al. (2007) collected data from a large sample of first-year college students and found that students of color reported feeling less of a sense of belonging than their white counterparts.

Race, ethnicity, and sexual orientation have received the most scholarly attention in studying students and belonging. Vaccaro et al. (2015) contended that disability is an identification that needs consideration as well. Their study is one of the first to explore belonging for students with disabilities aside from research examining the effect that campus infrastructure has on students with physical disabilities. Most of the students in the study had hidden 
disabilities such as mental health diagnoses. They conducted in-depth interviews with these students and found that sense of belonging was synergistically connected with self-advocacy, social relationships, and mastery of the student role. They also found that participants wanted to connect with other students with disabilities.

\section{THE ROLE OF OASS IN FACILITATING ENGAGEMENT AND BELONGING FOR STUDENTS WITH DISABILITIES}

Stereotypically speaking, students with disabilities have fewer connections to on-campus resources than students who do not have disabilities (Sachs \& Schreuer, 2011). The results of a study on the effect of social support on college students with disabilities yielded complex results about the type of social support that was most helpful but led the researchers to conclude that OASs and other units on campus should help students with disabilities to develop and maintain social relationships (Lombardi et al., 2014). While it is not necessary that students with disabilities connect with each other to achieve engagement and feel a sense of belonging, doing so could be uniquely beneficial (Strayhorn, 2012; Vaccaro et al., 2016).

Having relationships with other students who have disabilities may be a way to foster a positive disability identity. This term refers to claiming one's disability and having a favorable sense of self as a person with that disability. Research (Raver, et al., 2018) suggests that many students with disabilities do not incorporate their disability into their self-identity. However, embracing one's disability status can be very empowering. The same study found that having a positive disability identity was associated with a greater sense of belonging. Thus, it may be that the capacity of a college or university to engage students with disabilities will have a substantial impact on their sense of self.

Similarly, Cooper (2009) advocated helping students form and join affinity groups representing their distinct characteristics. Hall and Belch (2000) asserted that students with disabilities need a place where they can, "communicate honestly, authentic and intimate relationships are established, and a commitment is developed to sharing joys and sorrows together" (p. 10). The stigma associated with having a disability, and the challenges of identifying other students with disabilities (given that most disabilities are hidden), may make establishing affinity groups difficult for students to do on their own. OAS units may be the only unit on campus that can facilitate affinity groups for the students they serve.

There are numerous ways to build an affinity group for students with disabilities. We propose that a group centered around expressive arts is ideal for facilitating engagement and belonging for students with disabilities.

\section{USING EXPRESSIVE ARTS TO FACILITATE ENGAGEMENT AND BELONGING FOR STUDENTS WITH DISABILITIES}

Engaging in creative endeavors is a well-documented means of supporting physical and mental health (Abbott, et al., 2013). The visual arts, dance, music, creative writing, and other art modalities have been widely employed to treat the body and psyche. The known benefits provide the foundation for art and music therapy fields. The expressive arts can be a tool through which anyone may enhance their well-being (Jensen \& Bonde, 2018; Knill, et al., 2003; McNiff, 2004).

Less is known about how creating art alongside others, or collaboratively, may be beneficial. The concept of "third spaces" is relevant here. Third spaces/places are neither work nor home (Oldenburg, 1989). They are neutral grounds where people can enjoy and learn about each other, talk, and create relationships. Oldenburg noted that social media platforms are third spaces frequently used by young people, but the most promising third spaces are real places where people can gather.

Timm-Bottos and Reilly (2014) researched the benefits of a university-sponsored third space where people came together to create visual art. Their research led them to conclude that the simple act of joining with others to make art has a positive impact on the participants' social and emotional well-being. They asserted that the desire to make art is innate to human beings, can be aesthetically pleasing, and is a means for learning. They add that making art with other people allows us to see other viewpoints and "ways of knowing" (p. 105). Being with other people while 
making art can enhance our self-compassion and compassion for others. Their qualitative research of the experiences of people who used a community art center led them to conclude that:

The use of empowering third spaces and multiple ways of knowing can rebalance notions of authority, knowledge creation, and power and provide the medium that simultaneously promotes relevant, well-rounded, deep, and meaningful personal and professional educational experiences with the potential to go on to use the arts to promote healthy communities (p. 113).

Although she did not label her musical arts-based projects with children as third spaces, Nunn (2020) described how creating music with peers helped refugees express their intersecting identities as young people and connect to their refugee communities. Nunn noted that making art with others provided an "exceptional sphere of belonging" (p. 5). She explained that shared art spaces (i.e., third spaces) are unlike the locations we inhabit in everyday life. Nunn described creating art with others as, “... spaces of co-inquiry that are grounded in critical reflection and creative knowledge production" (p.5). Said differently, relationships are likely to develop as people express themselves through art and engage in free-flowing conversations that lead to interpersonal and meaningful insights. Nunn also concluded that shared art spaces were especially welcoming to marginalized populations.

\section{METHODS}

\section{Participants}

Participants were recruited through an email sent to students who use the services of the OAS at a mid-sized, private university. The email invited students to be part of a research project, spanning 3 group meetings, to discuss inclusivity on campus for students with disabilities and to participate in a shared art experience to facilitate discussion. Four students volunteered to be participants. One identified as male and the other three as female. Three of the participants had hidden disabilities (learning disability or a psychological disorder), and one had a physical disability requiring a wheelchair.

\section{Procedure}

We interviewed students about their campus experiences of inclusivity and offered a third space for creating art as a means for further data collection. Four volunteer participants who used the services of the OAS on our campus attended three sessions where they were interviewed and (a) taught an art technique; (b) taught to do the technique with a partner; and (c) used the technique with a guest whom they identified as having impacted their inclusivity on campus.

The first session began with a brief overview of the project. The PIs introduced the topic of inclusivity and the process of using an arts space. Everyone then participated in a 5-minute guided mindfulness exercise and brief, semi-structured interview about perceptions of inclusivity at the University. Afterward, the second PI demonstrated how to create a pour painting - an abstract painting created by layering acrylic paint and silicone products into a cup and then pouring the paint onto a canvas. Following the demonstration, the students and PIs made pour paintings (Figure 1). The meeting was audio-recorded.

\section{Figure 1}

Example of Pour Painting and Paintings Created During Session 1
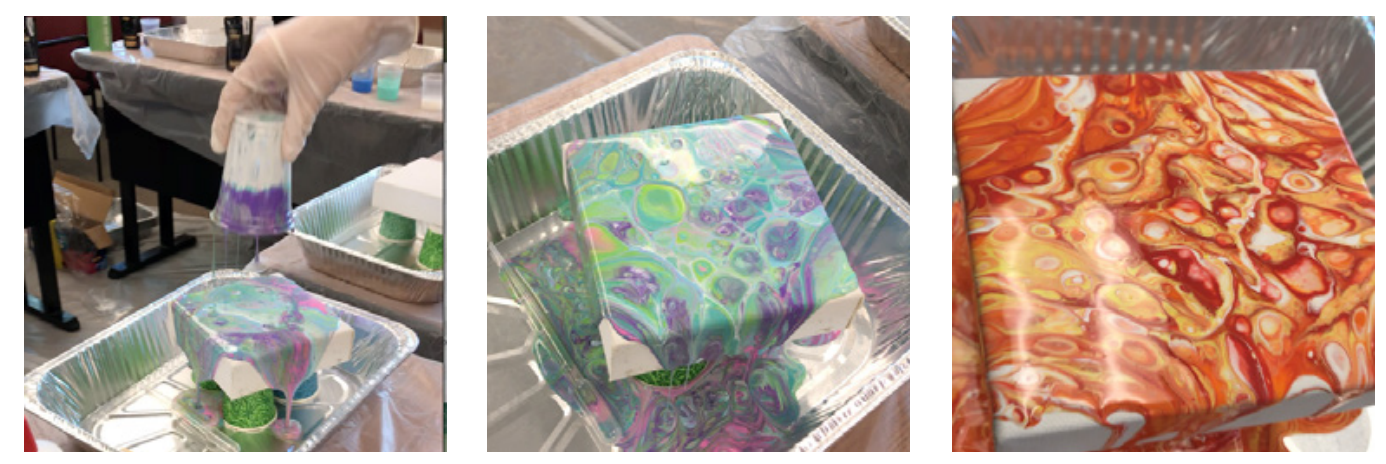
Meeting 2 began with a 2-minute mindfulness breathing exercise. Afterward, the participants shared their thoughts about the first meeting in a semi-structured interview. This was followed by a demonstration of co-creating a pour painting with a partner. The participants then formed pairs and practiced co-creating a pour painting. As before, the meeting was audio-recorded.

The final meeting started with a 2-minute guided imagery, and the participants were again interviewed in a semi-structured manner. Afterward, each participant and their guest went to a private room where they co-created two pour paintings (Figure 2). Before ending the meeting, the group gathered to talk about the experience. The portions of the meeting where everyone was together were audio-recorded.

\section{Figure 2}

Examples of Co-Created Pour Paintings Made with a Guest
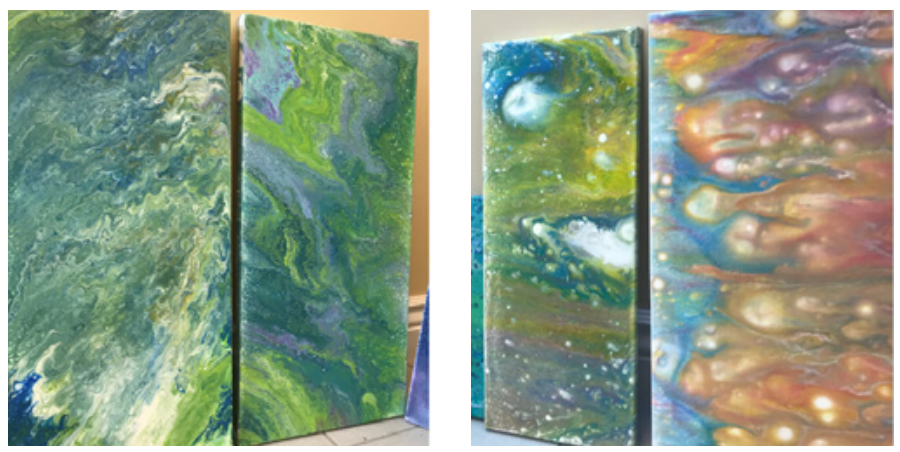

\section{Design}

The experience of creating art with peers who identify as having a disability could be studied in several ways. With a large sample size, researchers could administer surveys about the experience and analyze the data statistically. The risk of such a quantitative analysis is that the a priori assumptions of the researchers creating the surveys may not fully represent the participants' experience, so valuable information is lost. Qualitative methods are arguably the only way for researchers to gain a rich understanding of a situation or event or other human experience.

There are various qualitative methods, all with their own merits. For this study, the phenomenological method of Giorgi (1985) was used to evaluate the data because phenomenology is aimed at illustrating human experience and describing it in psychological terms. The typical data of phenomenology are transcribed in-depth, semi-structured interviews of people who have had a particular experience. The researchers engaged the participants in semi-structured interviews at the beginning of the three sessions for the present study. The interview data were supplemented by transcripts of spontaneous verbal statements and exchanges made while the participants co-created art.

\section{Data Analysis}

Data analysis involved several essential steps. The first PI adopted a presuppositionless attitude and studied the transcriptions to understand the main elements of "inclusivity" and each student's experience of creating art with fellow students with disabilities. Main elements - called units of meaning -- are those that the researcher deems to have psychological significance. The units of meaning were coded and restated from everyday language into psychological language. The units of meaning were then synthesized across participants to reveal themes, thus indicating the key features of the experience. The second PI reviewed the transcripts, coded units of meaning, and proposed themes for intersubjective agreement. Lastly, quotes that represent the themes were selected by both researchers. The essential themes that emerged were (a The desire for support beyond academic accommodations; (b) The benefits of an expressive arts program; (c) The meaning of inclusivity and desire for engagement and belonging. A phenomenological description of each theme follows in the Results section. 


\section{FINDINGS}

\section{The Desire for Support Beyond Academic Accommodations}

Participants spoke of needing institutional support in terms of academic accommodations. They noted that accommodations are essential for effective learning and allow them to demonstrate what they know. The participants expressed appreciation for their university's OAS. One participant commented on the recent change in the title of the Office from The Office of Disability Services to The Office of Accessibility Services and cited the change as an example of institutional support and validation.

However, across the sessions, the participants emphasized that they want support beyond the minimal requirement of academic accommodations. For example, talking about inclusivity prompted stories of the opposite - how needing accommodations sometimes led to exclusion. While the participants were clear to say that most faculty, staff, and students treat them respectfully, they want members of the campus community to receive education about disabilities in the hope that greater awareness and understanding will eliminate incidents of exclusion. One participant asked, "Will you include [in the research findings] what we told you about how [some students and faculty] here are unaware? I mean, I definitely think that it should be included because there are some people here that literally have no clue." Another participant said, "I think it's really important." The rest commented, "I totally agree with you on this" and "I do too."

To illustrate, one participant shared her experiences of repeatedly being singled out by a faculty member for receiving accommodations. The most egregious story she told was, "She [the professor] handed me my test, and she said, in front of the entire class, 'you need to go take this where you belong.' And I know that this was not how it is supposed to go down." All the participants spoke of how using accommodations sometimes draws attention, curiosity, and even hostility from their peers. For example, a participant reported that a student in one of her classes told her that getting extra time on tests, "wasn't fair," and that the student was going to complain to the professor.

A subtheme that emerged was that participants do not feel equipped to address stigma and discrimination when it happens. On two occasions, the participants queried each other about handling adverse situations. When a participant relayed a recent negative experience, she added, "And everyone was staring at me, and I was so upset I wanted to go home." Another participant said, "I have so much respect for you. I have a smart mouth...so props for you for being able to keep your cool." In a later session, after hearing of an incident, one participant asked, "Have you said anything back? Not to be an instigator, but I would not be able to take that." The participant who reported the negative experience answered, "No, I didn't want to ignore it, but I did bite my tongue... I just didn't want to start anything." When one of the PIs asked if the participants would like to learn how to respond to aversive situations diplomatically and assertively, they said they would like to be taught that skill.

\section{The Benefits of an Expressive Arts Program}

Three subthemes related to the benefits of an expressive arts program emerged. The first was that the participants enjoyed being in a "third space" together making art and found it psychologically beneficial. The second was that they found aesthetic pleasure in creating and having art, and the third was that making art facilitated easy sharing and connection. Each subtheme will be touched on briefly.

When the participants were directly interviewed about their first experience creating art together, they spoke enthusiastically about how much they enjoyed the session. One participant said, "I couldn't wait until the next one [second session] because it was so fun, and it was such a great experience." Another participant said, "Last time was something I really needed ... it was awesome." The first participant added, "It makes you feel like all of your burdens are gone, it takes reality away for a little while, and that is a good thing for me." Another said, "Usually I'm anxious, and I get really panicky, and this helps me not feel that way." In later sessions, they spontaneously offered comments about how making art together helped them combat the stress of school because it is, "calming" and "relaxing." In the final session, one participant said to another, "What I learned here is that there are no screw-ups. There is nothing that you can't fix." The other responded, "I feel like that is the first thing you have to accept when 
you go into art, that artists never make a mistake, they just make their paintings better." A third participant added, "I think it is also a lesson for me; I need to have that outlook for everything, not just doing art."

The participants frequently commented positively on the work they created and the work of each other. The transcripts are filled with, "I love that idea; color; the way that looks." Speaking of her own painting, one participant said, "That is gorgeous; it looks like expensive art, seriously." Another participant exclaimed, "I didn't expect it to come out the way it did, so it was awesome." Yet another told the group that she showed her paintings from the first session to her mother, and her mother was so impressed she told her daughter to bring the paintings home over the next break because she wanted one.

Having a concrete task allowed for easy engagement and the free flow of conversation. Throughout the sessions, the participants chatted and laughed together. They shared personal information about where they are from and their families, how they are doing in school, and advice on getting through some core courses. A participant sang out, "This girl is on fire," and the rest of the group joined in during one session. They also built bridges for further engagement. For example, during one session, a new participant was pleased to be told about activities that the OAS sponsors during Disability Awareness Month. Another member said, "We have it every year, so come and join us."

\section{The Meaning of Inclusivity and the Desire for Engagement and Belonging}

Participants initially spoke of inclusivity as "acceptance" and feeling comfortable in a diverse community regardless of personal characteristics. During the last session, they referred to inclusivity more concretely, as "coming together" and "belonging "in a community. Emphasis was also placed on the importance of making sure others feel included. One participant said, "not only feeling like you belong, but making sure that other people feel like they belong with you."

Across the sessions, connections between the participants deepened, and they expressed their appreciation for meeting each other and talking about shared experiences. In an early session, one participant asserted that many students have hidden disabilities, and so theoretically, she knew she was not alone, but that she was motivated to participate in the study because she wanted to know about the experiences of other students with disabilities. She said, "I want to share what has happened to me so that I can bond with the other students."

The participants spoke of feeling connected to the group during the later sessions. There was talk about "collaboration," and one participant said to another, "I appreciate you so much." They commented that painting helped them express themselves and see the other group members more deeply. When a participant spoke negatively about her artwork, another yelled out, "Hey, this is a judgment-free zone!" Several participants spoke of being perfectionistic and controlling about their artwork, which led to the group members sharing their vulnerabilities such as anxiety and being shy.

Over the three weeks of conducting the study, we all seemed to lose sight of the original purpose of the research. We were investigating the experience of inclusivity on campus for students with disabilities - our intention was not to facilitate engagement and belonging. Yet engagement and belonging were the ultimate outcomes. For example, when participants shared personal stories about disability discrimination, comments such as "This is a safe space" were offered as the group progressed. During the final session, when a participant apologized for "ranting," another told her, "This is totally not ranting." Then a third participant said, "That's what we're here for."

\section{Point of Interest}

One participant in the study said she wished the research would continue so the group would be maintained. The other participants agreed strongly and implored the PIs to facilitate an ongoing experience. With the support of our University OAS Director, the second PI agreed to provide a bi-monthly expressive arts program. The program introduced students to new expressive arts modalities and continued within the OAS for two semesters. The program then expanded to include a broader base of participants from across the University (7-20 students per session). A recent issue of the International Expressive Arts Therapy Association (IEATA) newsletter (for members only) highlights the work of the second PI. It describes how, due to the pandemic, she eventually continued her program virtually. For two hours every Sunday evening, she hosts a Zoom "open studio" where students can co-create art virtually. 


\section{Summary}

Our original intent was to learn how students with disabilities define and experience inclusivity within our campus community. The experiences we provided over three sessions of the study were designed to elicit that information. We obtained what we wanted but, in the process, we learned much more. We discovered that students with disabilities might benefit from services beyond accommodations. OAS units are uniquely poised to provide such additional support. For example, staff and students might hold workshops or classes to teach student advocacy and assertiveness skills. OAS units can facilitate campus community awareness and education. They may also create third spaces and activities for students with disabilities to come together and affiliate. We found engaging in expressive arts to be especially fruitful for fostering engagement and belonging.

\section{DISCUSSION}

We recommend that college and university OASs facilitate engagement and belonging for the students they serve by offering group experiences that allow students to identify each other and interact while engaging in an activity. Activities can be anything that students might enjoy. Still, we suggest that the activity promotes self-expression, so students have a greater opportunity to have a personally meaningful connection - more so than playing a game or engaging in a service project.

We found as Nunn (2020) attested, that creating art together provides an "exceptional sphere of belonging" (p. 5). Creating art is a pleasurable activity that students can do while also socializing with reduced social pressure. The work created becomes a means through which students can share themselves to the extent they are comfortable. They can engage with each other on the level of looking at each other's work or deepen their connection by revealing the meaning their work has or how it relates to their personal experiences. The student chooses the level of intimacy desired.

On a practical note, we recommend emphasizing the satisfaction of expression rather than the actual product. While there are benefits in offering instruction in a fail-proof art technique like pour-painting that practically guarantees a satisfying outcome, the most meaningful aspect of an expressive arts program is creating together. Interested readers are directed to the abundance of resources on the internet and through organizations like the IEATA (https://www.ieata.org/).

\section{REFERENCES}

Abbott, K. A., Shanahan, M. J., \& Neufeld, R. W. J. (2013). Artistic Tasks Outperform Nonartistic Tasks for Stress Reduction. Art Therapy, 30(2), 71-78. https://doi.org/10.1080/07421656.2013.787214

Americans with Disabilities Act. (1990). Public Law 101-336. 42 U.S.C. 12111, 12112.

Bureau of Labor Statistics, U.S. Department of Labor, The Economics Daily, People with a disability less likely to have completed a bachelor's degree.

https://www.bls.gov/opub/ted/2015/people-with-a-disability-less-likely-to-have-completed-a-bachelorsdegree.htm (visited August 29, 2021).

Cooper, R. (2009). Constructing Belonging in a Diverse Campus Community. Journal of College and Character, 10(3), 2-10. https://doi.org/10.2202/1940-1639.1085

DaDeppo, L. M. W. (2009). Integration Factors Related to the Academic Success and Intent to Persist of College Students with Learning Disabilities. Learning Disabilities Research \& Practice, 24(3), 122-131. https://doi.org/10.1111/j.1540-5826.2009.00286.x

Giorgi, A. (Ed.). (1985). Phenomenology and psychological research. Pittsburgh, PA: Duquesne University Press.

Hall, L. M., \& Belch, H. A. (2000). Setting the Context: Reconsidering the Principles of Full Participation and Meaningful Access for Students with Disabilities. New Directions for Student Services, 2000(91), 5-17. https://doi.org/10.1002/ss.9101 
Jensen, A., \& Bonde, L. (2018). The use of arts interventions for mental health and well-being in health settings. Perspectives in Public Health, 138(4), 209-214. https://doi.org/10.1177/1757913918772602

Johnson, D. R., Soldner, M., Leonard, J. B., Alvarez, P., Inkelas, K. K., Rowan-Kenyon, H. T., \& Longerbeam, S. D. (2007). Examining Sense of Belonging Among First-Year Undergraduates From Different Racial/Ethnic Groups. Journal of College Student Development, 48(5), 525-542. https://doi.org/10.1353/csd.2007.0054

Kimball, E., Friedensen, R. \& Silva, E (2017) Engaging disability: Trajectories of involvement for college students with disabilities. Disability as diversity in higher education: Policies and practices to enhance student success. Retrieved from https://scholarworks.umass.edu/cfssr_publishedwork/7

Knill, P. J., Barba, H. N. \& Fuchs, M. N. (2003). Minstrels of Soul (2nd ed.). Toronto, ON: E.G.S. Press.

Kuh, G. D. (2001). The National Survey of Student Engagement: Conceptual framework and overview of psychometric properties. Indiana University Center for Postsecondary Research and Planning. https:// scholarworks.iu.edu/dspace/handle/2022/24268

Kuh, G. D., Kinzie, J., Schuh, J. H., \& Whitt, E. J., \& Associates (2005). Student success in college: Creating conditions that matter. San Francisco, CA: Jossey-Bass.

Komives (2019). Engagement with campus activities matter: Toward a new era of educationally purposeful activities. The Journal of Campus Activities Practice and Scholarship, 1(1), 14-25. https://www.naca.org/ JCAPS/Documents/Komives_Article_JCAPS_Issue_1.pdf

Lam, S. F., Wong, B. P. H., Yang, H. F., \& Liu, Y. (2012). Understanding student engagement With a contextual model. In S. L. Christenson, A. L. Reschly, \& C. Wylie (Eds.), Handbook of research on student engagement (pp. 403-419). New York: Springer

Leavy P. (2018). Introduction to arts-based research. In: Leavy P (ed.), Handbook of Arts-Based Research. New York: The Guilford Press, 3-21.

Lombardi, A., Murray, C., \& Kowitt, J. (2016). Social support and academic success for college students with disabilities: Do relationship types matter? Journal of Vocational Rehabilitation, 44(1), 1-13. https://doi. org/10.3233/jvr-150776

Mahar, A. L., Cobigo, V. \& Stuart, H. (2013). Conceptualizing belonging. Disability and Rehabilitation: An International, Multidisciplinary Journal, 35(12), 1026-1032. https://doi.org/10.3109/09638288.2012.717584

McNiff, S. (2004). Art Heals: How Creativity Cures the Soul. Boston, MA: Shambhala Publications, Inc.

Newman, L. A., Madaus, J. W., Lalor, A. R., \& Javitz, H. S. (2020). Effect of accessing supports on higher education persistence of students with disabilities. Journal of Diversity in Higher Education. 14(3), 353-363. https://doi.org/10.1037/dhe0000170

Nunn, C. (2020). The participatory arts-based research project as an exceptional sphere of belonging. Qualitative Research. https://doi.org/10.1177/1468794120980971

Oldenburg, R. (1989). The great good place. New York: Paragon House.

Raver, A., Murchake, H., \& Chalk, H. M. (2018). Positive Disability Identity Predicts Sense of Belonging in Emerging Adults With a Disability. Psi Chi Journal of Psychological Research, 23(2), 157-165. https://doi. org/10.24839/2325-7342.jn23.2.157

Sachs, D., \& Schreuer, N. (2011). Inclusion of students with disabilities in higher education: Performance and participation in student's experiences. Disability Studies Quarterly, 31(2), 13. https://doi.org/10.18061/dsq. v31i2.1593

Schacter S. (1959) The psychology of affiliation. Experimental studies of the sources of gregariousness. Stanford, CA: Stanford University Press.

Strayhorn, T. L. (2012). College students' sense of belonging: A key to educational success for all students. New York, NY: Routledge.

Thorndike, E. (1932). The Fundamentals of Learning. New York: Teachers College Press. 
Timm-Bottos, J., \& Reilly, R. C. (2014). Learning in third spaces: Community art studio as storefront university classroom. American Journal of Community Psychology, 55, 102-114 (2015). https://doi.org/10.1007/s10464014-9688-5

Tinto, V. (2012). Leaving college: Rethinking the causes and cures of student attrition (2nd ed.). Chicago, IL: The University of Chicago Press.

U.S. Department of Education, National Center for Education Statistics. (2021). Digest of Education Statistics, 2019 (2021-009). Fast Facts: Students with disabilities, inclusion of (59) (ed.gov).

Vaccaro, A., Daly-Cano, M., \& Newman, B. (2015). A sense of belonging among college students with disabilities: An emergent theoretical model. Journal of College Student Development, 56(7), 670-686. https:// doi.org/10.1353/csd.2015.0072

Walton G. M., \& Cohen, G. L. (2011). A brief social-belonging intervention improves academic and health outcomes of minority students. Science, 331, 1447-1451. https://doi.org/10.1126/science.1198364

Zhoc, K.C.H., Webster, B.J., King, R.B., Johnson, C.H.L., \& Chung, T.S.H. (2019). Higher Education Student Engagement Scale (HESES): Development and psychometric evidence. Research in Higher Education, 60(2), 219-244. . https://doi.org/10.1007/s11162-018-9510-6 